\title{
Death certification by British doctors: a demographic analysis
}

\author{
ANDREW K DIEHL* AND DONALD W GAU \\ From the Department of Community Medicine, The Middlesex Hospital Medical School, Central Middlesex \\ Hospital, London NW10 7NS, UK
}

SUMMARY Regional differences in mortality from cardiovascular diseases, respiratory diseases, strokes, and other causes have been observed in England and Wales. To determine to what extent the death certification practices of doctors influence these variations, we surveyed 123 British general practitioners and housemen. Each doctor completed death certificates based on fictitious case histories. We found that diagnostic groupings did not vary significantly according to the doctors' region, type of practice, place of medical training, sex, or year of qualification. Doctors qualifying before 1955, however, appeared more inclined than their younger colleagues to list stomach cancer on the death certificate.

For over 100 years epidemiologists have noted a pronounced regional variation in mortality rates within England and Wales. In general, death rates are highest in the north and west and lowest in the south and east. Regional differences in mortality from specific causes of death are also evident, and with few exceptions follow the same geographic pattern. ${ }^{1-3}$

Mortality statistics are based on death certificates, and it is well established that these are often inaccurate in describing the "true" underlying cause of death. ${ }^{4}$ A doctor's place of residence and period of medical school education may influence his choice of diagnoses in completing death certificates. $^{56}$ Accordingly, we wondered whether some of the apparent regional variation in cause-specific mortality could be accounted for by systematic differences in diagnostic preferences among doctors in these regions. We have investigated this hypothesis in a survey of British general practitioners and housemen.

\section{Methods}

From maps showing cause-specific regional mortality ratios in England and Wales, ${ }^{1}$ we chose two regional health authorities with raised ratios (Wales and North-Western) and two with low ratios (East Anglian and South-Western). Within each regional health authority we selected one area health authority (Gwent, Rochdale, Suffolk, and Devon

\footnotetext{
-Milbank research fellow on leave from the Department of Medicine,
} University of Texas Health Science Center, San Antonio, Texas, USA. respectively) using a random numbers table. Lists of medical practitioners for each of these AHAs were obtained from family practitioner committees, and doctors were stratified according to their year of qualification using information provided in the Medical Directory. ${ }^{?}$

Thirty-nine doctors were randomly selected from each area list, 13 from each of three strata. Because most deaths now occur in hospitals, we also selected a random sample of housemen in medicine and geriatrics from lists provided by hospitals in each AHA. Thirteen housemen in each area were randomly selected.

We composed summaries of roughly 100 words each on 15 patients. These fictitious "cases" were written to cover a broad range of clinical conditions. Most cases concerned multiple pathologic processes, and death was often sudden and before diagnostic tests could be completed. (Copies of the patient summaries may be obtained from us on request.) Five patient summaries were written such that death could occur in or out of hospital; these five were sent to both general practitioners and housemen. The 10 remaining cases were characteristic either of a general-practice or hospital environment, and were divided between the study groups. Each survey participant was sent 10 patient summaries with standard death certificate forms attached and asked to complete the certificates as if the patients had been his own. Because many of the cases were difficult or ambiguous, each doctor was asked to state whether he would sign the certificate in real life. A reminder 
letter was sent one month later; a random sample of general practitioners still not responding after the reminder was contacted by telephone.

Completed death certificates were coded according to the International Classification of Diseases, ninth Revision (ICD), at the Office of Population Censuses and Surveys in London. Underlying causes of death appearing on the certificates were grouped into diagnostic categories for purposes of comparison. The Chi-square test was applied to the results.

\section{Results}

Forms were returned by 97 general practitioners (62\%) and 26 housemen (51\%). Overall response rates ranged from $53 \%$ in Rochdale to $65 \%$ in Suffolk. Among the general practitioners, response rates for each of the periods of qualification (before $1955,1955-64$, and 1965 and later) varied between 60 and $65 \%$. Many responding doctors commented on the difficulty of the cases and the unexpected length of time required to complete the certificates. Because of their frequent changes of hospital jobs, housemen were difficult to recontact after the first mailing of the survey. These factors probably affected the response rate. Overall, $90 \%$ of the respondents were men. Ninety-one $(74 \%)$ had attended medical school in England, seven in Wales, six in Scotland, one in Northern Ireland, eight in the Irish Republic, and 10 in other countries.

All doctors examined the first five patient summaries. The underlying causes of death given for these cases were grouped into seven broad categories as shown in table 1 . The distribution of diagnoses in these categories did not differ between general practitioners and housemen, nor did it differ on the basis of the doctor's medical school location. There was no significant difference in distribution among these categories according to the doctor's sex. The findings were unchanged when the analysis was restricted to those cases in which the doctors would be willing to complete the certificate in real life.

The 97 responding general practitioners examined 10 identical patient summaries. The underlying causes given on these certificates were tabulated and grouped into nine diagnostic categories as shown in table 2. The distribution of diagnoses did not differ significantly among the four areas, or when the two high mortality areas were compared with the two low ones. Likewise, when doctors were separated by their era of qualification, no systematic difference in the distribution of diagnoses was observed. These results held when the analysis was limited to those certificates that the doctors would sign under usual circumstances. Case 9 described an elderly woman with a wasting disease and abdominal symptoms. Sixteen general practitioners $(16.5 \%)$ ascribed her death to stomach cancer (ICD 151.9). Of those doctors who qualified before 1955, $10(29.4 \%)$ diagnosed stomach cancer, as opposed to six (9.5\%) of those doctors qualifying later $(p<0 \cdot 05)$. Rather than certifying stomach cancer, the younger doctors more often listed other cancers (especially those of the gastrointestinal tract), or offered no diagnosis at all. No variation in the diagnosis of stomach cancer was seen between regions.

Table 1 Distribution of underlying causes of death given for first five cases, by doctors' characteristics

\begin{tabular}{|c|c|c|c|c|c|c|c|}
\hline \multirow[b]{2}{*}{$\begin{array}{l}\text { Diagnostic category } \\
\text { (ICD codes) }\end{array}$} & & \multirow[b]{2}{*}{ All doctors } & \multicolumn{2}{|c|}{ Type of practice } & \multicolumn{3}{|c|}{ Location of medical school } \\
\hline & & & $\begin{array}{l}\text { General } \\
\text { practitioners }\end{array}$ & Housemen & England & $\begin{array}{l}\text { Other } \\
\text { British and Irish }\end{array}$ & $\begin{array}{l}\text { Outside } \\
\text { British Isles }\end{array}$ \\
\hline $\begin{array}{l}\text { Neoplasms } \\
\text { (140-239) } \\
\text { Diabetes } \\
\text { (250) } \\
\text { Cerebrovascular disease } \\
\text { (430-438) } \\
\text { Other circulatory system } \\
\text { (390-429, 440-459) } \\
\text { Respiratory diseases } \\
\text { (460-519) } \\
\text { Genitourinary diseases } \\
\text { (580-629) } \\
\text { Other diagnoses } \\
\text { (All other codes) } \\
\text { No diagnosis } \\
\text { All certificates } \\
\text { All doctors }\end{array}$ & $\begin{array}{r}\text { No } \\
\% \\
\text { No } \\
\% \\
\text { No } \\
\% \\
\text { No } \\
\% \\
\text { No } \\
\% \\
\text { No } \\
\% \\
\text { No } \\
\% \\
\text { No } \\
\% \\
\text { No } \\
\%\end{array}$ & $\begin{array}{c}42 \\
6 \cdot 8 \\
41 \\
6 \cdot 7 \\
111 \\
18 \cdot 0 \\
104 \\
16 \cdot 9 \\
172 \\
28 \cdot 0 \\
112 \\
18 \cdot 2 \\
4 \\
0 \cdot 7 \\
29 \\
4 \cdot 7 \\
615 \\
100 \\
123\end{array}$ & $\begin{array}{c}34 \\
7 \cdot 0 \\
33 \\
6 \cdot 8 \\
88 \\
18 \cdot 1 \\
78 \\
16 \cdot 1 \\
136 \\
28 \cdot 0 \\
88 \\
18 \cdot 1 \\
3 \\
0 \cdot 6 \\
25 \\
5 \cdot 2 \\
485 \\
100 \\
97\end{array}$ & $\begin{array}{l}8 \\
6 \cdot 2 \\
8 \\
6 \cdot 2 \\
23 \\
17 \cdot 7 \\
26 \\
20 \cdot 0 \\
36 \\
27 \cdot 8 \\
24 \\
18 \cdot 5 \\
1 \\
0 \cdot 8 \\
4 \\
3 \cdot 1 \\
130 \\
100 \\
26\end{array}$ & $\begin{array}{c}30 \\
6 \cdot 6 \\
28 \\
6 \cdot 2 \\
84 \\
18 \cdot 5 \\
77 \\
16 \cdot 9 \\
133 \\
29 \cdot 2 \\
83 \\
18 \cdot 2 \\
2 \\
0 \cdot 4 \\
18 \\
4 \cdot 0 \\
455 \\
100 \\
91\end{array}$ & $\begin{array}{c}6 \\
5 \cdot 5 \\
6 \\
5 \cdot 5 \\
21 \\
19 \cdot 1 \\
16 \\
14 \cdot 5 \\
30 \\
27 \cdot 3 \\
20 \\
18 \cdot 2 \\
1 \\
0 \cdot 9 \\
10 \\
9 \cdot 0 \\
110 \\
100 \\
22\end{array}$ & $\begin{array}{c}6 \\
12 \cdot 0 \\
7 \\
14 \cdot 0 \\
6 \\
12 \cdot 0 \\
11 \\
22 \cdot 0 \\
9 \\
18 \cdot 0 \\
9 \\
18 \cdot 0 \\
1 \\
2 \cdot 0 \\
1 \\
2 \cdot 0 \\
50 \\
100 \\
10\end{array}$ \\
\hline
\end{tabular}


Table 2 Distribution of underlying causes of death given for 10 cases: general practitioners

\begin{tabular}{|c|c|c|c|c|c|c|c|}
\hline \multirow[b]{2}{*}{$\begin{array}{l}\text { Diagnostic category } \\
\text { (ICD codes) }\end{array}$} & & \multirow[b]{2}{*}{$A l l G P s$} & \multicolumn{2}{|c|}{ Practice location } & \multicolumn{3}{|c|}{ Year of qualification } \\
\hline & & & $\begin{array}{l}\text { Rochdale + } \\
\text { Gwent }\end{array}$ & $\begin{array}{l}\text { Devon + } \\
\text { Suffolk }\end{array}$ & Before 1955 & $1955-64$ & After 1964 \\
\hline $\begin{array}{l}\text { Neoplasms } \\
\text { (140-239) } \\
\text { Diabetes } \\
\text { (250) } \\
\text { Ischaemic heart disease } \\
\text { (410-414) } \\
\text { Cerebrovascular disease } \\
\text { (430-438) } \\
\text { Other circulatory system } \\
\text { (390-405, 415-429, 440-459) } \\
\text { Respiratory disease } \\
\text { (460-519) } \\
\text { Digestive disease } \\
\text { (520-579) } \\
\text { Genitourinary disease } \\
\text { (580-629) } \\
\text { Other diagnoses } \\
\text { (All other codes) } \\
\text { No diagnosis } \\
\text { All certificates } \\
\text { All doctors }\end{array}$ & $\begin{array}{r}\text { No } \\
\% \\
\text { No } \\
\% \\
\text { No } \\
\% \\
\text { No } \\
\% \\
\text { No } \\
\% \\
\text { No } \\
\% \\
\text { No } \\
\% \\
\text { No } \\
\% \\
\text { No } \\
\% \\
\text { No } \\
\% \\
\text { No } \\
\%\end{array}$ & \begin{tabular}{|l|}
99 \\
$10 \cdot 2$ \\
38 \\
$3 \cdot 9$ \\
120 \\
$12 \cdot 4$ \\
121 \\
$12 \cdot 5$ \\
90 \\
$9 \cdot 3$ \\
191 \\
$19 \cdot 7$ \\
85 \\
$8 \cdot 8$ \\
88 \\
$9 \cdot 1$ \\
14 \\
$1 \cdot 4$ \\
124 \\
$12 \cdot 8$ \\
970 \\
100 \\
97
\end{tabular} & $\begin{array}{l}48 \\
10 \cdot 4 \\
23 \\
5 \cdot 0 \\
58 \\
12 \cdot 6 \\
53 \\
11 \cdot 5 \\
46 \\
10 \cdot 0 \\
87 \\
18 \cdot 9 \\
41 \\
8 \cdot 9 \\
39 \\
8 \cdot 5 \\
9 \\
2 \cdot 0 \\
56 \\
12 \cdot 2 \\
460 \\
100 \\
46\end{array}$ & $\begin{array}{c}51 \\
10 \cdot 0 \\
15 \\
2 \cdot 9 \\
62 \\
12 \cdot 2 \\
68 \\
13 \cdot 3 \\
44 \\
8 \cdot 6 \\
104 \\
20 \cdot 4 \\
44 \\
8 \cdot 6 \\
49 \\
9 \cdot 6 \\
5 \\
1 \cdot 0 \\
68 \\
13 \cdot 3 \\
510 \\
100 \\
51\end{array}$ & $\begin{array}{l}36 \\
10 \cdot 6 \\
12 \\
3 \cdot 5 \\
38 \\
11 \cdot 2 \\
45 \\
13 \cdot 2 \\
35 \\
10 \cdot 3 \\
70 \\
20 \cdot 6 \\
30 \\
8 \cdot 8 \\
30 \\
8 \cdot 8 \\
3 \\
0 \cdot 9 \\
41 \\
12 \cdot 1 \\
340 \\
100 \\
34\end{array}$ & $\begin{array}{c}30 \\
9 \cdot 7 \\
14 \\
4 \cdot 5 \\
41 \\
13 \cdot 2 \\
39 \\
12 \cdot 6 \\
28 \\
9 \cdot 0 \\
59 \\
19 \cdot 0 \\
28 \\
9 \cdot 0 \\
28 \\
9 \cdot 0 \\
4 \\
1 \cdot 3 \\
39 \\
12 \cdot 6 \\
310 \\
100 \\
31 \\
\text { p }=\mathrm{NS}\end{array}$ & $\begin{array}{c}33 \\
10 \cdot 3 \\
12 \\
3 \cdot 8 \\
41 \\
12 \cdot 8 \\
37 \\
11 \cdot 6 \\
27 \\
8 \cdot 4 \\
62 \\
19 \cdot 4 \\
27 \\
8 \cdot 4 \\
30 \\
9 \cdot 4 \\
7 \\
2 \cdot 2 \\
44 \\
13 \cdot 8 \\
320 \\
100 \\
32\end{array}$ \\
\hline
\end{tabular}

\section{Discussion}

It has long been recognised that total death rates in northern England and southern Wales are substantially higher than those in the south and east of England. This geographic pattern also holds for most broad categories of mortality, including diseases of the circulatory system, respiratory system, cerebrovascular disease, and accidents, poisoning, and violence. Most malignant neoplasms have a uniform distribution of mortality across England and Wales, stomach cancer being a notable exception. ${ }^{1-3}$

The death certificates on which these mortality figures rest often inaccurately reflect the underlying pathology resulting in death. "The doctor completing the certificate must usually do so without the benefit of necropsy findings. Although he may include what he believes to be the underlying cause of death on the certificate, the clerk who codes for statistical purposes may choose an entry elsewhere on the form after applying basic coding rules. Finally, the doctor's period of medical training or practice location may influence his choice of diagnosis used on death certificates. In a study similar to ours doctors in London were found to list "chronic bronchitis" on death certificates more often than did American or Norwegian doctors reviewing identical cases. ${ }^{5}$ Older Irish doctors have been found to use diagnoses such as "senility" or "myocardial degeneration" more often than do their younger counterparts.

We therefore wondered whether the striking variation in regional mortality within England and
Wales could be partly accounted for by the certification practices of the doctors in these areas. By submitting identical case summaries to a random sample of British doctors, we have been able to perform such a demographic analysis. Once the resulting diagnoses were grouped into broad categories, we found the doctors practising in these areas to have similar certification habits. It appears unlikely that the differences in standardised mortality ratios for, say, diseases of the respiratory system (men, 117 in North Western and 122 in South Wales, 81 in East Anglia and South Western) ${ }^{1}$ can be explained as certification artefact.

Diagnostic groupings also did not differ systematically between housemen and general practitioners, between men and women, or among graduates of medical schools in several countries. Among general practitioners, the distribution of diagnoses by broad categories was not related to the doctors' era of qualification. The specific diagnosis of stomach cancer, however, was used significantly more often by general practitioners who qualified before 1955 . This suggests that the falling mortality from stomach cancer may be partially accounted for by the replacement of older doctors by younger ones less inclined to write this diagnosis on death certificates. The fall in stomach cancer mortality, however, has been pronounced while the turnover in doctors has been gradual. We feel this proposed "generational" bias in reporting cancer of the stomach could play only a secondary role in its reported decline. 
Death certification is a more subjective process than most doctors or health statisticians would care to admit. It does not appear, however, that demographic characteristics of doctors can explain the regional differences in broad categories of mortality observed in England and Wales. The determination of the true causes of these geographic patterns remains a challenge to epidemiologists and health planners.

We thank Dr Peter Goldblatt of the Office of Population Censuses and Surveys for arranging the coding of the certificates, Mr Stephen Edmeades for his statistical help, and the 123 British doctors who kindly participated in the survey. Dr Diehl is a Millbank scholar in epidemiology.
Reprints from Dr Diehl, Division of General Medicine, Robert B Green Memorial Hospital, 4502 Medical Drive, San Antonio, Texas 78284, USA.

\section{References}

${ }^{1}$ Chilvers C. Regional mortality 1969-73. Population Trends 1978; 11: 16-20.

${ }^{2}$ Chilvers C, Adelstein A. Cancer mortality: the regional pattern. Population Trends 1978; 12: 4-9.

${ }^{3}$ Acheson R, Sanderson C. Strokes: social class and geography. Population Trends 1978; 12: 13-7.

Anonymous. Uncertain certificates. Lancet 1981; ii: 22-3.

${ }^{5}$ Reid DD, Rose GA. Assessing the comparability of mortality statistics. Br Med J 1964; ii: 1437-9.

'Bourke GJ, Hall MA. A study of some certified causes of death and age of the certifying doctor. Journal of the Irish Medical Association 1968; 61: 115-22.

'Medical Directory. London: Churchill Livingstone, 1980. 